\title{
Comparison of Acid Secretory Responsiveness to Gastrin Heptadecapeptide and of Gastrin Heptadecapeptide Pharmacokinetics in Duodenal Ulcer Patients and Normal Subjects
}

\author{
A. John Blair III, Charles T. Richardson, Michael Vasko, John H. Walsh, and Mark Feldman \\ Departments of Internal Medicine, Surgery, and Pharmacology, University of Texas Southwestern Medical School, Dallas, Texas 75235; \\ Veterans Administration Medical Centers, Dallas, Texas 75216 and West Los Angeles, California 90073; and University of California \\ at Los Angeles School of Medicine, Los Angeles, California 90073
}

\begin{abstract}
Serum gastrin concentrations and gastric acid secretion were measured during intravenous infusion of gastrin heptadecapeptide (G-17) $(0,7,22.1,70,221$, and $700 \mathrm{pmol} / \mathrm{kg} \cdot \mathrm{h})$ in 15 duodenal ulcer patients and 15 healthy controls. Ulcer patients developed higher serum gastrin concentrations during $\mathbf{G - 1 7}$ infusion due to nearly twofold slower clearance of gastrin (8.8 vs. $15.7 \mathrm{ml} /$ $\mathrm{kg} \cdot \mathrm{min} ; P<0.01)$. Despite slower clearance of $\mathrm{G}-17$, ulcer patients had plasma elimination half-times for G-17 similar to controls (6.0 vs. $6.1 \mathrm{~min}$, respectively). Thus, calculated volume of distribution for G-17 was lower in ulcer patients than controls (78.5 vs. $140.7 \mathrm{ml} / \mathrm{kg} ; \boldsymbol{P}<0.025$ ). For any serum gastrin during gastrin-17 infusion, acid secretion (millimoles per hour) was higher in ulcer patients than in controls. However, when acid secretion was expressed as a percentage of peak acid output to G-17 (to correct for differences in parietal cell mass), curves relating acid secretion to serum gastrin were identical in ulcer patients and controls.
\end{abstract}

\section{Introduction}

Gastrin is a major endogenous stimulant of gastric acid secretion, especially after a meal $(1,2)$. Studies by Isenberg, Lam, and their associates have suggested that parietal cells of patients with duodenal ulcer $(\mathrm{DU})^{1}$ are more responsive to gastrin than parietal cells of normal subjects $(2,3)$. This is controversial, however, since acid secretory responsiveness to exogenous gastrin was similar in DU patients and controls studied by Hirschowitz et al. $(4,5)$. In the present study, we compared acid secretory responsiveness to human gastrin heptadecapeptide (G-17) in DU patients and controls. By infusing G-17 intravenously and by measuring acid secretion and serum gastrin concentrations simultaneously, we were able to relate acid secretion not only to the dose of exogenous G-17 infused but also to circulating gastrin levels. By measuring serum gastrin concentration during G-17 infusion, we could also compare metabolic clearance rates,

Portions of this work were presented at the American Gastroenterological Association Meeting, New York, NY, May, 1985 and were published in abstract form, 1985. Gastroenterology. 88:1328.

Address correspondence to Dr. Feldman, Veterans Administration Medical Center (151), 4500 South Lancaster Rd., Dallas, TX 75216.

Received for publication 5 December 1985 and in revised form 24 March 1986.

1. Abbreviations used in this paper: DU, duodenal ulcer; G-17, gastrin heptadecapeptide; Ke, plasma elimination rate for gastrin; PAO, peak acid output; Vd, volume of distribution.

The Journal of Clinical Investigation, Inc.

Volume 78, September 1986, 779-783 elimination half-times, and volumes of distribution for G-17 in the two groups.

\section{Methods}

Studies were approved by the Human Research Review Committee of the Veterans Administration Medical Center, Dallas, TX. All patients and subjects gave written consent before participation in these experiments.

DU Patients and controls. 15 patients (12 male) with prior DU documented by upper gastrointestinal $x$-ray and/or endoscopy were studied. Their mean $( \pm \mathrm{SE})$ age was $49 \pm 3 \mathrm{yr}$ and their weights averaged $75.7 \pm 3.6$ $\mathrm{kg}$ (Table I). All patients were asymptomatic at the time of these experiments. If patients were receiving antisecretory medications, these medications were discontinued $48 \mathrm{~h}$ before each study. The control group consisted of 15 healthy subjects ( 12 male) with an average age of $31 \pm 2$ yr and an average weight of $71.5 \pm 3.5 \mathrm{~kg}$ (Table I). Basal acid output and peak acid output to $6 \mu \mathrm{g} / \mathrm{kg}$ subcutaneous pentagastrin (PAO), measured in a preliminary study as previously described (6), averaged $7.4 \pm 1.8$ and $46.4 \pm 3.0 \mathrm{mmol} / \mathrm{h}$ in the DU patients compared with $2.4 \pm 0.6$ and $31.7 \pm 2.8 \mathrm{mmol} / \mathrm{h}$ in controls $(P<0.02$ for basal acid output and $P$ $<0.005$ for PAO). Each DU patient and normal subject was then studied after an overnight fast, as described below.

G-17 infusion protocol. An intravenous catheter was placed in each arm and kept open by slow infusions of $0.15 \mathrm{M} \mathrm{NaCl}$. A nasogastric tube was positioned in the dependent portion of the stomach under fluoroscopic guidance and residual gastric secretions were evacuated manually. After a 45-min basal period during which $0.15 \mathrm{M} \mathrm{NaCl}$ was infused intravenously, a solution of G-17 (synthetic human G-17-I; Research Plus, Bayonne, NJ) dissolved in $0.15 \mathrm{M} \mathrm{NaCl}$ and containing $1 \%$ human albumin was infused in doses of 7, 22.1, 70, 221, and $700 \mathrm{pmol} /$ $\mathrm{kg} \cdot \mathrm{h}$. Each G-17 dose was infused over a 45 -min period in a stepwise fashion (infusion pump 922; IMED Corp., San Diego, CA). Gastric secretions were collected by aspiration using a Stedman suction pump (American Cystoscope Makers, Inc., Stamford, CN), with suction applied for 48 out of every $60 \mathrm{~s}$. Each sample of gastric juice was collected for $15 \mathrm{~min}$. The volume was measured and the hydrogen ion concentration was determined by titration to $\mathrm{pH} 7.00$ with $0.1 \mathrm{~N} \mathrm{NaOH}$. Acid output was calculated by multiplying volume times hydrogen ion concentration.

Blood specimens for serum gastrin assay were obtained from the catheter that had been placed in the arm opposite the G-17 infusion site. Specimens were drawn at the beginning of the experiment and also at $30,37.5$, and $45 \mathrm{~min}$ after beginning each $45-\mathrm{min}$ infusion of $\mathrm{NaCl}$ or $\mathrm{G}-17$. At the end of the $700 \mathrm{pmol} / \mathrm{kg} \cdot \mathrm{h} \mathrm{G}-17$ infusion, the infusion pump was turned off and additional blood specimens were obtained after $2,5,10,15$, and $30 \mathrm{~min}$ in order to compare plasma elimination rates for G-17 in the two groups of subjects (see below).

Serum gastrin radioimmunoassay. Because of the large number of sera (720 in all), two separate gastrin assays were necessary. Samples were divided so that an equal number from the DU and control groups could be included in each assay. Sera were coded and shipped from Dallas, TX to Los Angeles, CA on dry ice. Serum gastrin concentration was measured using antibody 1611 as previously described (7). The three serum gastrin values for each G-17 dose were similar (mean coefficients of variation were $13,13,12,12$, and $13 \%$ for G-17 doses of $7,22.1,70$, 
Table I. Age, Weight, Metabolic Clearance Rates, Elimination Half-times, and Vd in 15 DU Patients and in 15 Normal Controls*

\begin{tabular}{|c|c|c|c|c|c|c|c|c|c|c|}
\hline & \multicolumn{5}{|c|}{ DU patients } & \multicolumn{5}{|c|}{ Normal controls } \\
\hline & Age & Weight & $\mathrm{Cl}$ & $t_{1 / 2}$ & vd & Age & Weight & $\mathrm{Cl}$ & $t_{1 / 2}$ & Vd \\
\hline & $y r$ & $k g$ & & & & $y r$ & $\mathrm{~kg}$ & & & \\
\hline 1 & 23 & 60.0 & 4.4 & 4.1 & 26.7 & 21 & 70.0 & 14.2 & 2.9 & 60.0 \\
\hline 2 & 31 & 78.6 & 3.6 & 3.7 & 19.1 & 23 & 75.9 & 10.6 & 4.2 & 64.6 \\
\hline 3 & 38 & 69.5 & 11.3 & 6.8 & 110.8 & 24 & 71.4 & 3.8 & 7.2 & 39.2 \\
\hline 4 & 41 & 56.8 & 16.1 & 6.0 & 139.1 & 24 & 72.7 & 4.9 & 5.5 & 38.5 \\
\hline 5 & 46 & 97.7 & 11.1 & 6.1 & 97.2 & 25 & 62.7 & 20.1 & 6.2 & 180.2 \\
\hline 6 & 50 & 82.7 & 11.1 & 6.3 & 101.6 & 28 & 63.6 & 14.6 & 5.1 & 108.0 \\
\hline 7 & 50 & 95.0 & 3.1 & 7.7 & 34.7 & 29 & 77.7 & 23.3 & 6.8 & 229.1 \\
\hline 8 & 50 & 65.9 & 14.3 & 6.8 & 139.6 & 30 & 80.9 & 10.1 & 5.3 & 77.9 \\
\hline 9 & 51 & 79.5 & 11.6 & 6.6 & 109.4 & 31 & 52.3 & 17.1 & 10.1 & 246.7 \\
\hline 10 & 54 & 64.5 & 10.8 & 5.3 & 82.2 & 31 & 68.2 & 21.2 & 10.0 & 306.5 \\
\hline 11 & 55 & 52.3 & 11.0 & 7.0 & 110.9 & 33 & 64.5 & 24.8 & 4.6 & 165.9 \\
\hline 12 & 57 & 85.5 & 4.3 & 6.1 & 37.4 & 34 & 80.9 & 9.4 & 6.0 & 81.6 \\
\hline 13 & 59 & 86.0 & 4.9 & 4.1 & 29.1 & 41 & 83.6 & 24.6 & 7.0 & 247.6 \\
\hline 14 & 61 & 88.0 & 9.3 & 6.6 & 88.6 & 42 & 46.4 & 6.0 & 6.5 & 56.0 \\
\hline 15 & 63 & 75.0 & 5.0 & 7.1 & 50.7 & 46 & 102.3 & 30.7 & 4.7 & 209.2 \\
\hline Mean & $49 \ddagger$ & 75.7 & $8.8 \ddagger$ & 6.0 & $78.5 \ddagger$ & 31 & 71.5 & 15.7 & 6.1 & 140.7 \\
\hline SEM & 3 & 3.6 & 1.1 & 0.3 & 10.8 & 2 & 3.5 & 2.1 & 0.5 & 23.3 \\
\hline
\end{tabular}

$\mathrm{Cl}$, metabolic clearance rate. * Clearance in milliliters per kilograms times minutes, elimination half-time in minutes, and Vd in milliliters per kilograms were calculated from serum gastrin data during and after infusion of $700 \mathrm{pmol} / \mathrm{kg} \cdot \mathrm{h} \mathrm{G}-17$ (see text for equations). $¥ P<0.025$ versus normal controls.

221 , and $700 \mathrm{pmol} / \mathrm{kg} \cdot \mathrm{h}$ in DU patients and $10,15,14,15$, and $16 \%$, respectively, in controls). Therefore, the three serum gastrin values for each dose were averaged and then related to the acid secretion rate for the 15-min period during which gastrin was measured.

Statistics. Differences between mean results in DU patients and controls were tested by unpaired Student's $t$ test. Probability values $<0.05$ were considered significant. Correlation coefficients were calculated by linear regression analysis.

\section{Results}

Serum gastrin concentration. As shown in Fig. $1 A$, basal serum gastrin concentrations were identical in DU patients and controls. On the other hand, steady-state serum gastrin concentrations during G-17 infusion in DU patients were approximately twice those of controls, and differences reached statistical significance with G-17 doses of 221 and $700 \mathrm{pmol} / \mathrm{kg} \cdot \mathrm{h}(P<0.01)$. From serum gastrin data during and after discontinuation of G17 infusion (Fig. $1 A$ ), we calculated and compared G-17 clearance rates, elimination half-times, and volumes of distribution in the two groups.

G-17 clearance. Clearance of G-17 was calculated by two methods. In the first method, G-17 dose was plotted against steady-state serum gastrin concentration. In both DU patients and controls, this relationship was linear $(r=0.99 \pm 0.003$ and $0.99 \pm 0.01$, respectively). Results using mean data for DU patients and controls are shown in Fig. 2. It is apparent from Fig. 2 that the slopes of the regression lines were different in DU patients and controls. Since the reciprocal of the slopes of each line (in kilograms times minutes per milliliter) represents clearance of G-17 in milliliters per kilograms times minutes, the mean data show that the clearance of G-17 in DU patients was slower than in controls. When clearance was determined in each patient and subject from the slopes of their own regression equations, clearance averaged $8.6 \pm 1.1 \mathrm{ml} / \mathrm{kg} \cdot \mathrm{min}$ in DU patients and $14.8 \pm 1.9 \mathrm{ml} / \mathrm{kg} \cdot \mathrm{min}$ in controls $(P<0.01)$.

Clearance was also calculated using the plateau principle from the following equation: clearance $=$ G-17 infusion rate/ $\Delta G$, where $\Delta G$ is the steady-state basal-subtracted serum gastrin concentration $(8,9)$. We used serum gastrin concentrations during infusion of $700 \mathrm{pmol} / \mathrm{kg} \cdot \mathrm{h} \mathrm{G}-17$ (Fig. $1 \mathrm{~A}$ ). As shown in Table I, clearance was $8.8 \pm 1.1$ and $15.7 \pm 2.1 \mathrm{ml} / \mathrm{kg} \cdot \min$ for DU patients and controls, respectively $(P<0.01)$. Thus, regardless of the method used to calculate clearance (slope or plateau principle), DU patients cleared G-17 approximately half as rapidly as controls.

G-17 plasma elimination half-life. After discontinuing the $700 \mathrm{pmol} / \mathrm{kg} \cdot \mathrm{h} \mathrm{G}-17$ infusion, basal-subtracted serum gastrin concentrations were used to determine the plasma elimination rate for gastrin $(\mathrm{Ke})$ (Fig. $1 \mathrm{~A}$ ). Initial pharmacokinetic parameter estimates were determined using the CSTRIP computer program (10). We then used an iterative nonlinear least-squares fitting program, NONLIN, to fit each set of data and obtain final estimates of the parameters (11). Since the elimination data best fit a one-compartment model $(r=0.99 \pm 0.002$ for DU patients; $r=0.98 \pm 0.066$ for controls), $\mathrm{Ke}$ was determined as the negative slope of the decay curve. Elimination half-time in minutes was then calculated by the equation: $t_{1 / 2}=0.693 / \mathrm{Ke}$. As shown in Table I, half-time was not significantly different in DU patients and controls ( $6.0 \pm 0.3$ vs. $6.1 \pm 0.5 \mathrm{~min}$, respectively).

G-17 volume of distribution (Vd). Vd for G-17 was calculated by the equation: $\mathrm{Vd}=$ clearance/Ke (9). As shown in Table I, Vd was $78.5 \pm 10.8 \mathrm{ml} / \mathrm{kg}$ in DU patients and $140.7 \pm 23.3 \mathrm{ml} /$ $\mathrm{kg}$ in controls $(P<0.025)$. Thus, DU patients had both a slower clearance of G-17 and a smaller volume of distribution than controls. 

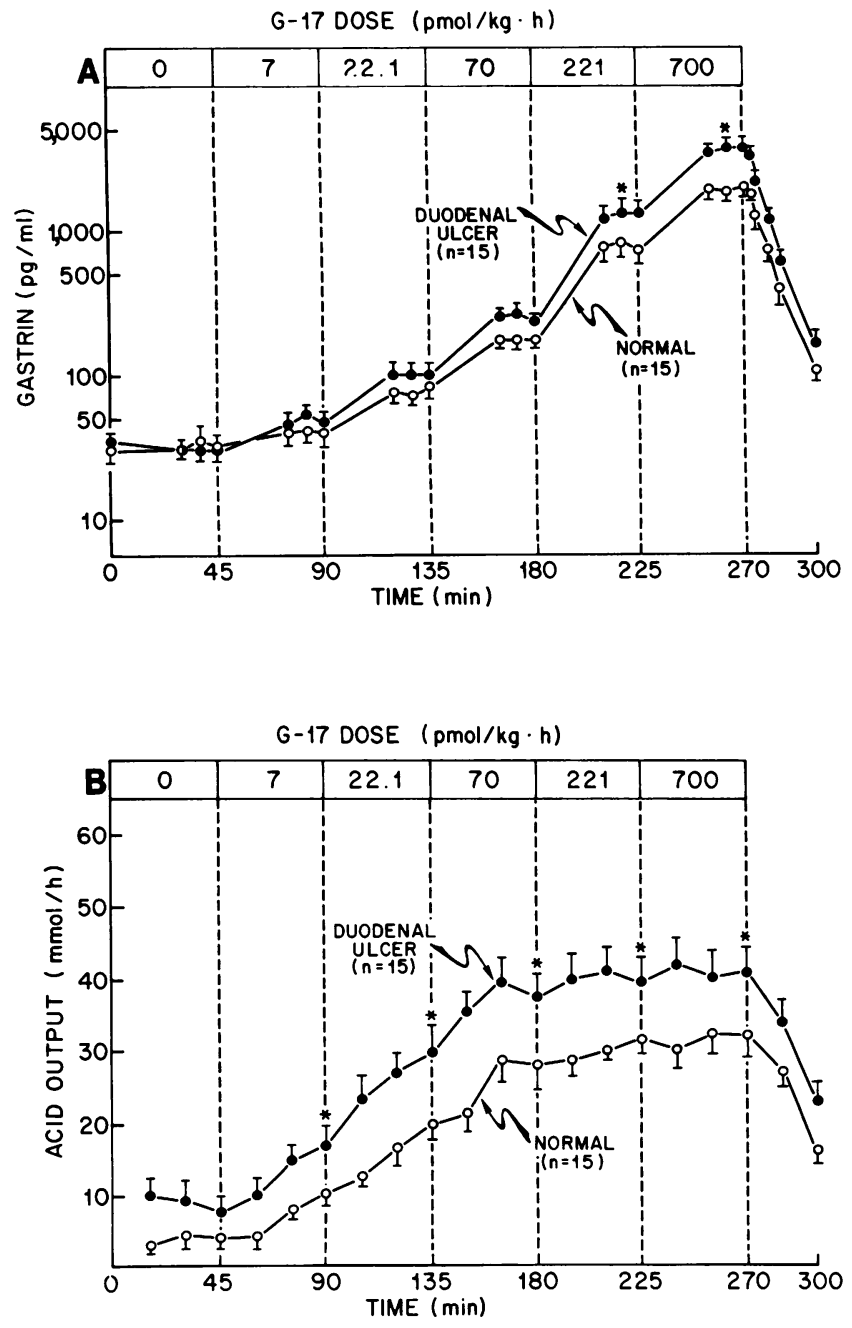

Figure 1. $(A)$ Mean $( \pm \mathrm{SE})$ serum gastrin concentration basally and during the last 15-min period of each intravenous G-17 dose, and for the 30-min period after termination of the G-17 infusion in $15 \mathrm{DU}$ patients and in 15 normal controls. Significant differences in average steady-state serum gastrin concentrations are shown by asterisks. $(B)$ Mean ( \pm SE) acid output for each group basally, during intravenous G17 infusion, and for $30 \mathrm{~min}$ after termination of G-17 infusion. Each point represents the mean acid output during a 15-min collection. Significant differences in acid output during the last 15 min of each G-17 infusion are shown by asterisks.

Acid secretion. For each G-17 dose (7, 22.1, 70, 221, and $700 \mathrm{pmol} / \mathrm{kg} \cdot \mathrm{h})$, mean acid output was significantly higher in DU patients than controls (Fig. 1 B). Maximal acid output was achieved with the $70 \mathrm{pmol} / \mathrm{kg} \cdot \mathrm{h}$ dose in both groups. When mean $( \pm \mathrm{SE})$ steady-state serum gastrin concentrations for each G-17 dose were plotted against corresponding acid outputs, mean acid output was higher in DU patients than controls for any given serum gastrin concentration (Fig. $3 A$ ). To correct for differences in PAO and parietal cell mass between DU patients and controls, acid output was also expressed as a percent of PAO (Fig. 3 B). Curves relating serum gastrin concentration to acid output expressed as a percent of PAO were identical, suggesting equal sensitivity to circulating gastrin in the two groups. Sensitivity was further examined by calculating the $50 \%$ effective dose $\left(E_{50}\right)$ for $\mathrm{G}-17$ and the $50 \%$ effective concentration $\left(E_{50}\right)$ for circulating gastrin (see below).

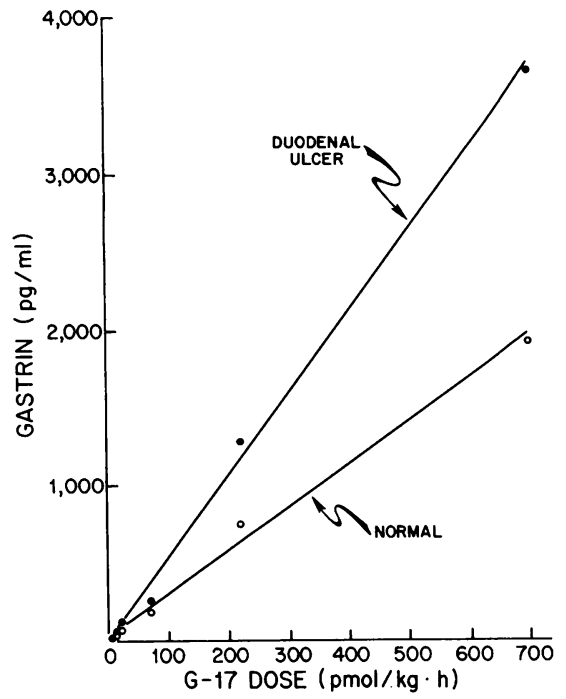

Figure 2. Relationship between intravenous G-17 dose and mean steady-state serum-gastrin concentration in 15 DU patients and 15 normal controls. In both cases, the relationship was linear $(r=0.999$ and 0.996 , respectively). The reciprocals of the slopes of these lines reflect G-17 clearance (see text).

$E D_{50}$. A linear relationship existed between $\log$ G-17 dose and acid output expressed as a percent of PAO (using G-17 doses of 7-70 pmol $/ \mathrm{kg} \cdot \mathrm{h}$ ). For example, correlation coefficients in DU patients averaged 0.95 \pm 0.02 (range, 0.69-1.00) and correlation coefficients in controls averaged $0.96 \pm 0.01$ (range, $0.87-$ 1.00). The 30 individual linear regression equations were solved for the $\log$ G-17 dose corresponding to an acid output of $50 \%$ of PAO, and then this log dose was converted to the $\mathrm{ED}_{50}$ in picomoles per kilograms times hours. As shown in Fig. $4 \mathrm{~A}$, mean $\mathrm{ED}_{50}$ was lower in DU patients than in controls (12.4 2.4 vs. $20.6 \pm 5.5 \mathrm{pmol} / \mathrm{kg} \cdot \mathrm{h}$ ), but this difference was not significant.

$E C_{50}$. There was a linear relationship between $\log$ serum gastrin concentration (using G-17 doses of 0-70 pmol/ $\mathrm{kg} \cdot \mathrm{h}$ ) and acid output expressed as a percentage of PAO $(r=0.97 \pm 0.01$ in DU; range, $0.90-1.00 ; r=0.96 \pm 0.02$ in controls; range, 0.75 1.00). Individual linear regression equations were solved for the log serum gastrin concentration corresponding to an acid output of $50 \%$ of PAO, and then the log concentration was converted to serum gastrin concentration in picograms per milliliter $\left(\mathrm{EC}_{50}\right)$. As shown in Fig. 4, mean $\mathrm{EC}_{50}$ was not significantly different in DU patients and controls ( $74 \pm 12 \mathrm{vs.} 63 \pm 14 \mathrm{pg} / \mathrm{ml}$, respectively). Thus, as defined by $\mathrm{EC}_{50}$, DU patients and controls were equally responsive to circulating gastrin.

\section{Discussion}

A major purpose of our study was to compare parietal cell responsiveness to G-17 in DU patients and controls. To compare responsiveness to a stimulant such as gastrin, differences in parietal cell mass must be considered. From the classic studies of Card and Marks, parietal cell mass is thought to correlate closely with PAO (12). In our study, mean PAO to G-17 (and to pentagastrin) was significantly higher in DU patients than controls, reflecting an increased parietal cell mass (13). To correct for differences in parietal cell mass, acid secretion in response to the stimulant is conventionally expressed as a percentage of PAO. Then, $\mathrm{ED}_{50}$ (i.e., the dose of stimulant required to produce $50 \%$ 

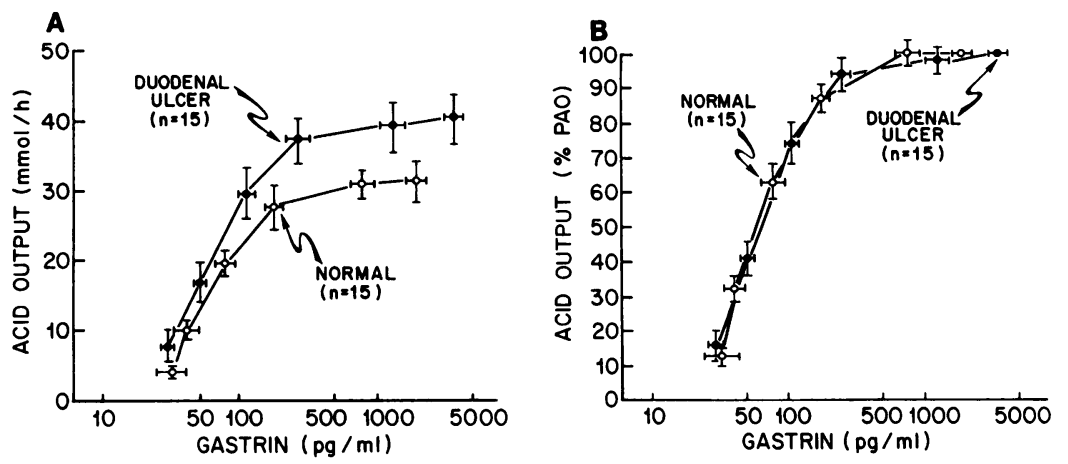

Figure 3. (A) Relationship between mean $( \pm \mathrm{SE})$ acid output during the last 15 -min period of each G-17 infusion and mean $( \pm \mathrm{SE})$ steady-state serum gastrin concentrations in 15 DU patients and 15 normal controls. $(B)$ Relationship between mean $( \pm \mathrm{SE})$ acid output as a percentage of PAO to $700 \mathrm{pmol} / \mathrm{kg} \cdot \mathrm{h} \mathrm{G}-17$ and mean $( \pm \mathrm{SE})$ steady-state serum gastrin concentration.

of PAO) can be compared in the two groups as indices of parietal cell responsiveness to the stimulant.

Different linear transformations of dose-response data have been used to calculate $\mathrm{ED}_{50}$ to gastrin. For example, Lam et al. (2) and Isenberg et al. (3) used the Dowd-Riggs linear transformation of the Michaelis-Menten equation $(14,15)$, and they reported a lower mean $\mathrm{ED}_{50}$ to gastrin in DU patients. However, their own dose-response data often did not fit this linear transformation particularly well. In Lam's G-17 study, median correlation coefficients were only 0.66 in normal subjects (range, $0.34-0.99$ ) and 0.81 in DU patients (range, 0.50-0.99). Furthermore, in Isenberg's pentagastrin study, correlation coefficients averaged only 0.62 in normal subjects (range, $0-0.96$ ) and 0.78 in DU patients (range, 0.24-0.98). We, too, initially analyzed our G-17 dose-response data using the Dowd-Riggs linear transformation of the Michaelis-Menten equation and our correlation coefficients were likewise not consistently high, averaging 0.81 in normal subjects (range, 0.19-1.00) and 0.85 in DU patients (range, 0.04-1.00). Thus, a linear transformation of the Michaelis-Menten equation does not always allow an accurate assessment of $\mathrm{ED}_{50}$, since $\mathrm{ED}_{50}$ is determined from the slope of the individual linear regression equations $(14,15)$.

In contrast to the Michaelis-Menten equation, we found a much better linear relationship between $\log$ G-17 dose and acid output expressed as a percent of PAO. In 29 of the 30 subjects studied, the correlation coefficient was $\geq 0.87$ and in the majority of individuals the correlation was $\geq 0.97$. This linear relationship
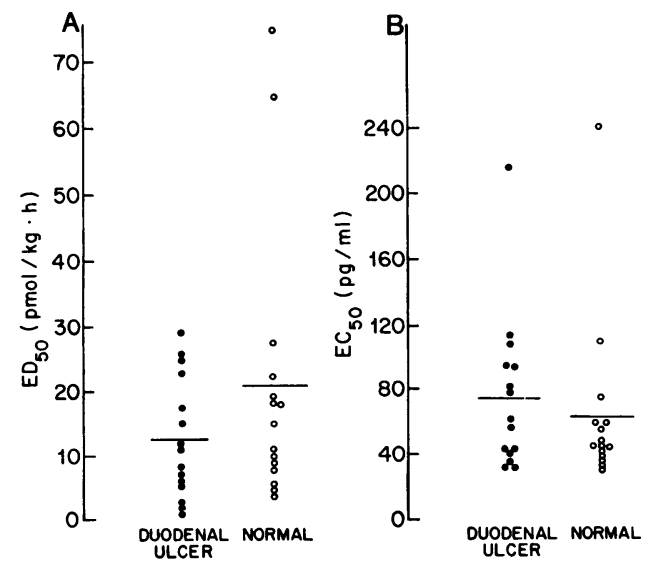

Figure 4. $(A)$ Estimated G-17 dose which gives $50 \%$ of peak acid output $\left(\mathrm{ED}_{50}\right)$ in 15 DU patients and 15 normal controls (NL). (B) Estimated serum gastrin concentration during G-17 infusion which gives $50 \%$ of peak acid output $\left(\mathrm{EC}_{50}\right)$. Mean $\mathrm{ED}_{50}$ and $\mathrm{EC}_{50}$ values are represented by horizontal lines. See text for calculation of $E_{50}$ and $E C_{50}$. between $\log$ dose and response allowed a fairly accurate estimation of individual $\mathrm{ED}_{50}$ values (Fig. 4). Using this logarithmic method, we found that mean $\mathrm{ED}_{50}$ was not significantly different in DU patients and controls. This finding is in agreement with the results of Hirschowitz et al., who used an exponential equation to calculate $\mathrm{ED}_{50}$ to pentagastrin and to $\mathrm{G}-17$ in DU patients and controls (4, 5). Hirschowitz excluded ulcer patients and controls whose dose-response data did not fit his exponential equation with a correlation coefficient of at least 0.87 . Using this 0.87 cutoff, Hirschowitz excluded $8 \%$ of DU patients, $31 \%$ of gastric ulcer patients, and 19\% of normal controls before making statistical comparisons of sensitivity to pentagastrin in ulcer patients and controls (4). In our study, none of the $30 \mathrm{DU}$ patients or controls was excluded from $\mathrm{ED}_{50}$ analysis.

In general, circulating serum concentrations of exogenous drugs or hormones more accurately correlate with response than does the dose administered. Consequently, we also compared sensitivity to G-17 in DU patients and controls as a function of serum gastrin concentrations rather than dose of gastrin infused. Our use of serum concentrations was important, since DU patients had considerably higher steady-state serum gastrin concentrations than controls for a given dose of exogenous G-17. When we calculated $\mathrm{EC}_{50}$ for circulating gastrin, no difference could be demonstrated between DU patients and controls (Fig. $3 \mathrm{~B}$ and Fig. $4 \mathrm{~B}$ ). Therefore, our results indicate that parietal cells of DU patients and normal controls have identical responsiveness (sensitivity) to circulating human G-17, a conclusion recently reached by Hirschowitz et al. (5).

An unexpected finding in this study was that DU patients had a slower clearance of exogenous G-17 and a smaller volume of distribution for G-17 than did controls. In contrast to our results, Eysselein et al. reported similar metabolic clearance rates and volumes of distribution for G-17 in five DU patients and six controls with mean ages similar to those in our study (7). It is unclear why our DU patients had a smaller apparent volume of distribution than our controls, yet the observed differences in clearance can only be explained by differences in distribution, since elimination rate constants were similar. G-17 elimination half-lives of $\sim 6$ min in DU patients and controls have been previously reported $(7,16)$.

We considered the possibility that differences in gastrin pharmacokinetics in our DU patients and controls could be related to the DU patients' older mean age. However, we were unable to find a significant correlation between age and metabolic clearance $(r=-0.30)$ or volume of distribution $(r=-0.20)$. Furthermore, clearance and volume of distribution of G-17 in our five youngest DU patients (mean age, $36 \mathrm{yr}$ ) averaged 9.3 $\mathrm{ml} / \mathrm{kg} \cdot \mathrm{min}$ and $78.6 \mathrm{ml} / \mathrm{kg}$, respectively, while clearance and 
volume of distribution in our five oldest normal controls (mean age, $39 \mathrm{yr}$ ) averaged $19.1 \mathrm{ml} / \mathrm{kg} \cdot \mathrm{min}$ and $152.1 \mathrm{ml} / \mathrm{kg}$, respectively (Table I). Thus, age is an unlikely explanation for the almost twofold differences in clearance and volume of distribution we observed between DU patients and healthy subjects. Whether the alteration in clearance of G-17 in DU patients is of clinical importance remains unknown.

\section{Acknowledgments}

The authors wish to thank Tina Barnett, Mary Walker, Julie Oliver, and Peter Chew for expert technical assistance, Pat Ladd for medical illustrations, and Vicky Lee Slagle for preparing the manuscript.

This work was supported by grants 16816 and 17294 from the National Institutes of Health and the Veterans Administration.

\section{References}

1. Feldman, M., J. H. Walsh, H. C. Wong, and C. T. Richardson. 1978. Role of gastrin heptadecapeptide in the acid secretory response to amino acids in man. J. Clin. Invest. 61:308-313.

2. Lam, S. K., J. I. Isenberg, M. I. Grossman, W. H. Lane, and J. H. Walsh. 1980. Gastric acid secretion is abnormally sensitive to endogenous gastrin released after peptone test meals in duodenal ulcer patients. J. Clin. Invest. 65:555-562.

3. Isenberg, J. I., M. I. Grossman, V. Maxwell, and J. H. Walsh. 1975. Increased sensitivity to stimulation of acid secretion by pentagastrin in duodenal ulcer. J. Clin. Invest. 55:330-337.

4. Hirschowitz, B. I. 1984. Apparent and intrinsic sensitivity to pentagastrin of acid and pepsin secretion in peptic ulcer. Gastroenterology. 86:843-851.
5. Hirschowitz, B. I., L. O. Tim, C. A. Helman, and E. Molina. 1985. Bombesin and G-17 dose responses in duodenal ulcer and controls. Dig. Dis. Sci. 30:1092-1103.

6. Feldman, M., and C. T. Richardson. 1981. Gastric acid secretion in humans. In Physiology of the Gastrointestinal Tract. L. R. Johnson, editor, Raven Press, New York. 693-707.

7. Eysselein, V. E., V. Maxwell, T. Reedy, E. Wunsch, and J. H. Walsh. 1984. Similar acid stimulatory potencies of synthetic human big and little gastrins in man. J. Clin. Invest. 73:1284-1290.

8. Goldstein, A. L., L. Aronow, and S. M. Kalman. 1974. Principles of Drug Action. John Wiley and Sons, New York. 311-318.

9. Gibaldi, M., and D. Perrier. 1982. Pharmacokinetics. Marcel Dekker, Inc., New York. 27-31.

10. Sedman, A. J., and J. G. Wagner. 1976. CSTRIP, a Fortran IV computer program for obtaining initial polyexponential parameter estimates. J. Pharm. Sci. 65:1006-1010.

11. Metzler, C. M., G. L. Elfring, and A. J. McEwen. 1974. A package of computer program for pharmacokinetic modeling. Biometrics. 30: 562 (Abstr.).

12. Card, W. I., and I. N. Marks. 1960. The relationship between the acid output of the stomach following "maximal" histamine stimulation and the parietal cell mass. Clin. Sci. (Lond.). 19:147-163.

13. Cox, A. J. 1952. Stomach size and its relation to chronic peptic ulcer. AMA (American Medical Association) Arch. Pathol. 54:407-422.

14. Dowd, J. E., and D. S. Riggs. 1965. A comparison of estimates of Michaelis-Menten kinetic constants from various linear transformations. J. Biol. Chem. 240:683-869.

15. Grossman, M. I. 1973. What do you do with basal in dose-response studies? A suggested answer. Gastroenterology. 65:341-344.

16. Walsh, J. H., J. I. Isenberg, J. Ansfield, and V. Maxwell. 1976. Clearance and acid-stimulating action of human big and little gastrins in duodenal ulcer subjects. J. Clin. Invest. 57:1125-1131. 